American Journal of Pharmaceutical Education 2019; 83 (9) Article 7379.

\title{
RESEARCH
}

\section{Student Pharmacists' Perspectives on Service-Learning Experiences in Free Clinics}

\author{
Jennifer Ko, PharmD, ${ }^{\mathrm{a}}$ Sharon Connor, PharmD, ${ }^{\mathrm{b}}$ Lauren Jonkman, PharmD, MPH, \\ Olufunmilola Abraham, $\mathrm{PhD}, \mathrm{MS}^{\mathrm{c}}$ \\ ${ }^{a}$ University of Pittsburgh Medical Center, Pittsburgh, Pennsylvania \\ ${ }^{\mathrm{b}}$ University of Pittsburgh School of Pharmacy, Pittsburgh, Pennsylvania \\ ${ }^{c}$ University of Wisconsin-Madison School of Pharmacy, Madison, Wisconsin \\ Submitted September 11, 2018; accepted January 30, 2019; published November 2019.
}

Objective. To explore student pharmacists' perspectives on the value of pharmacy-related servicelearning experiences focused on caring for underserved populations.

Methods. Student pharmacists were required to complete a three-hour volunteer experience at a free clinic in western Pennsylvania. Reflective essays from all second- and third-year student pharmacists who participated in the required service-learning experience were deidentified. Essays were thematically analyzed to formulate a list of codes that represent dominant conceptual categories. Two independent coders read and coded all essays submitted from September 2015 to May 2017 using qualitative data analysis. Codes were evaluated for intercoder variability and discrepancies were mediated through discussion.

Results. Four hundred twenty-two students submitted reflective essays: 222 essays were submitted by second-year students and 200 by third-year students. The prevailing themes reflected the professional obligation students felt to provide care to the underserved, empathy for underserved patients, perspectives on equitable health resource distribution, the value of service-learning experiences, growth in interprofessional awareness, and self-reported empowerment from the experience. Themes were consistent in the reflective essays of both second-year and third-year students. Third-year students' essays reflected a greater sense of self-assurance and confidence in their role at the free clinics. Students made connections between their didactic learning and experiential education.

Conclusion. Student pharmacists valued their experiences working in underserved settings. Free clinics provide opportunities for student pharmacists to develop hands-on training as well as gain a broader perspective on underserved populations, health resource distribution, and the role of pharmacists.

Keywords: service-learning, free clinics, health disparities, pharmacy students, underserved care

\section{INTRODUCTION}

Despite medical advances, disparities in health and health care continue to pervade society. ${ }^{1,2}$ Over the past few decades, addressing health disparities has been a priority for the US health care system, for private and public stakeholders alike. ${ }^{1}$ Promotion of health equity must be incorporated into the training of future health care professionals to reduce and eventually eliminate these disparities.

As a pragmatic form of experiential education that also supports societal needs, service-learning provides the unique opportunity to address disparities in care while providing a dynamic experiential environment to strengthen student skills. ${ }^{3}$ As the pharmacy profession continually progresses toward active involvement in

Corresponding Author: Sharon Connor, University of Pittsburgh, 5607 Baum Blvd., Rm. 303, Pittsburgh, PA 15206. Tel: 412-648-7192. Email: sconnor@pitt.edu. direct patient care, schools of pharmacy have been increasingly incorporating service-learning into curriculums over the past two decades. ${ }^{4,5}$ Accrediting agencies such as the Accreditation Council for Pharmacy Education (ACPE) and professional organizations such as the American Association of Colleges of Pharmacy (AACP) recognize the value of service-learning for fostering future pharmacists who serve individual, community, and societal needs, as well as seek justice in the distribution of health resources as outlined in the Code of Ethics for pharmacists. ${ }^{6}$

The benefits of service-learning have gained increased recognition in health care education, specifically with publications in dental medicine, medicine, and nursing education literature. ${ }^{3}$ As of 2015, all participants in the 2013-2014 AACP Academic Leadership Fellows program indicated that students in their professional 


\section{American Journal of Pharmaceutical Education 2019; 83 (9) Article 7379.}

programs were engaged in community service to varying extents; $85 \%$ of respondents indicated that a service-learning component was incorporated in their program. ${ }^{3}$ However, service-learning encompasses a wide variety of communitybased settings, and little has been published about servicelearning in free clinics. Further, there is a lack of existing research that provides a longitudinal assessment of student perceptions on service-learning experiences, involves a robust sample size, or assesses service-learning experiences that specifically incorporate pharmacy practice. ${ }^{3,7-12} \mathrm{Ex}-$ ploring the value of service-learning in limited-resource settings can better guide pharmacy curriculum development and assess its impact on developing socially responsible, empathetic pharmacists.

This study aimed to explore student pharmacists' perspectives on the value of pharmacy-related servicelearning experiences focused on caring for underserved populations. The objectives of this study were to describe how student pharmacists perceive the role of the pharmacist in helping vulnerable, underserved populations, including their professional obligation to serve; to determine whether exposure to working with underserved populations serves as a self-reported transformative experience or increases reported empathy for these populations; to assess whether this experience teaches students equitable distribution of health resources; and to evaluate whether students find this a valuable experience and one that helps them provide care in the context of their future career.

\section{METHODS}

At the University of Pittsburgh School of Pharmacy where the study was conducted, service-learning was required and integrated into all four years of the PharmD curriculum. ${ }^{13}$ In their second and third professional years, students were required to complete three hours of servicelearning each academic year at a free clinic as a part of the curriculum for their introductory pharmacy practice experiences (IPPEs). As service-learning requires structured reflection to optimize learning, students were required to submit a brief reflective essay within one week of completing their service experience. Prior to the clinic experience, students were given learning objectives and prompts to guide their reflection before attending the clinic (Table 1). Upon completion of the clinic experience, students were asked to write a one- to two-page essay addressing five reflective questions (Table 1). This assignment was designed to guide students when engaging in the reflective component of service learning. All clinic sites provided free health care services to homeless and/or uninsured or underinsured individuals in the form of primary care clinics or drop-in centers in an urban city in Western Pennsylvania. Partners included free clinics, a women's shelter, and two Health Care for the Homeless clinics. These clinics engage an interdisciplinary health care team to provide medical services and medications to patients at no cost.

All essays completed between September 2015 and May 2017 were included in this analysis, which represented P2s and P3s in the classes of 2018, 2019, and 2020. The University of Pittsburgh Human Research Protection Office approved this analysis of essays completed for the course.

Data analysis was conducted retrospectively on student reflective essays submitted to the Blackboard Learn (Blackboard Inc., Washington, DC) virtual learning environment and course management system from September 2015 to May 2017. All reflective essays were de-identified prior to analysis. Content reflected in the essays regarding the service-learning experience were qualitatively analyzed using open and axial coding originating with the raw data.

Table 1. Objectives and Reflection Prompts for Student Pharmacists Who Participated in Service-Learning Experiences in Free Clinics

\section{Objectives}

Participate with interprofessional health care team members in the management of, and health promotion for, all patients

Establish a climate of shared values and mutual respect to optimize outcomes for specific patient care encounters

Demonstrate an attitude that is respectful of different cultures

Demonstrate altruism, integrity, trustworthiness, flexibility, and respect in all interactions

Display preparation, initiative, and accountability consistent with a commitment to excellence

Deliver patient-centered care in a manner that is legal, ethical, and compassionate

Reflection Prompts

What were your expectations of the underserved clinic site before you arrived? Were your expectations met? In what ways was it the same or different from how you expected?

How did your experience at the clinic make you feel? How did your interactions with the patients impact you?

Who were the volunteer and staff members at the clinic? Describe the interprofessional team. In what ways did they work together effectively or ineffectively?

What was your role at the clinic? What would you do differently if you were to go again?

What was the most significant learning point from the experience? 


\section{American Journal of Pharmaceutical Education 2019; 83 (9) Article 7379.}

Essays were thematically analyzed to formulate a list of codes that represented dominant conceptual categories. Two independent coders read and coded all reflective essays submitted from September 2015 to May 2017 using NVivo, version 10 (QSR International, Melbourne, Australia) assisted qualitative data analysis. To ensure study rigor and reliability, coders used a consistent codebook that was collaboratively developed. Reflection essays were multi-coded if multiple themes were addressed. During research team meetings, coding discrepancies were examined and resolved. The most frequently used codes were then categorized to identify prevailing themes that comprehensively described student perceptions. Themes were identified by coder consensus through discussion.

\section{RESULTS}

Four hundred twenty-two reflection essays were included in the analysis: 222 from second-year students and 200 third-year students. The majority of students completed the service-learning experience at one free clinic, the largest of the sites (Table 2). Two independent coders reviewed the reflection essays and came to a consensus on four overall themes that addressed the research objectives; two additional themes were identified through the review process based on frequency of codes (Appendix 1). The kappa statistic for the two independent coders was 0.64 , which indicates modest intercoder reliability. Themes were consistent across the essays of both second- and third-year students.

The first theme identified in the students' essays was that they viewed providing care to the underserved and vulnerable as a professional obligation. Both second- and third-year student pharmacists expressed that health care professionals have an obligation to treat all patients with respect and provide the best possible care. Students shared that encounters with patients who had language or cultural barriers enriched their learning experience and enabled a greater appreciation for providing culturally sensitive care. Witnessing provider interactions with culturally diverse patients also enabled students to appreciate the rapport that is developed when health care professionals are sensitive to patients' backgrounds. Third-year student pharmacists expressed a greater sense of obligation and commitment to providing care to underserved populations than did secondyear student pharmacists. Students reflected "ownership" of this obligation as health care professionals. Additionally, students translated this obligation to provide care for underserved populations to patients in a variety of settings outside of free clinics. The obligation to provide culturally sensitive care served as a major learning point when interacting with patients with language barriers, and students expressed that the lessons learned in this context were important for developing effective communication skills.

The second theme identified was that working with the underserved increased students' empathy for these populations. Second-year students expressed a greater sense of empathy for low-income patient populations and appreciation for the care provided by the free clinic volunteers. However, some students expressed that the empathy they felt towards patients took an emotional toll. However, these overwhelming emotions also served as a source of motivation to continue providing care to the underserved. Thirdyear students expressed the emotional impact of in-person encounters with patients who had experienced challenging circumstances. However, this nurtured a deeper respect in students for patients who opened up and told their stories to the health care providers. Students also related the experiences they had with patients encountered at the free clinics to simulated patient experiences, and how students need opportunities to develop a greater appreciation for the problems that face people in real life.

The third theme identified was students' greater awareness of the inequities of the US health system. Students' exposure to underserved populations sparked deeper commentary on the US health system as a whole. Many second-year student pharmacists felt helpful while at the clinic, but sensed that a greater underlying issue existed. Some students felt very strongly that there was a degree of injustice in health resource distribution. These strong emotions led to students expressing negative attitudes toward the service-learning experience. Furthermore, some students were less optimistic about the US health care system and the utility of free clinics as a whole after the experience. These

Table 2. Distribution of Student Pharmacists at Clinic Sites for Service-Learning Experiences

\begin{tabular}{lccrrr}
\hline Site & P2 (2015-2016) & P2 (2016-2017) & P3 (2014-2015) & P3 (2015-2016) & Total \\
\hline Free clinic \#1 & 84 & 80 & 65 & 62 \\
HCH clinic \#1 & 0 & 0 & 0 & 8 \\
Free clinic \#2 & 14 & 2 & 10 & 8 \\
Women's center & 16 & 8 & 15 & 3 \\
HCH clinic \#2 & 8 & 8 & 5 & 20 \\
Unspecified & 2 & 0 & 3 & 3 \\
\hline
\end{tabular}

Abbreviations: $\mathrm{P} 2=$ second professional year; $\mathrm{P} 3=$ third professional year; $\mathrm{HCH}=$ Health Care for the Homeless 


\section{American Journal of Pharmaceutical Education 2019; 83 (9) Article 7379.}

students expressed that free clinics did not fix the underlying problems with the health care system and were at best a short-term fix. Third-year student pharmacists commonly described the way in which free clinics fit into health care access and the US health system as a whole.

The fourth theme identified was that students believed providing care to underserved populations in free clinics was a valuable experience. Many second-year students expressed that the experience was valuable. A few second-year students stated they would seek to pursue a career path that focused on the underserved or would want to volunteer in a similar capacity in the future. Many third-year student pharmacists expressed similar sentiments. Even if they had no intention to work in underserved settings in the future, they reflected on how the lessons learned from this experience could be applied to other settings.

The fifth theme identified was student growth in interprofessional awareness. Being exposed to a variety of patient-provider interactions enabled students to assess different approaches to patient care. Many second-year student pharmacists expressed the importance of interprofessional collaboration, and that health care provision was a joint effort. They acknowledged that it would be difficult for patients to receive adequate and comprehensive care without collaboration among health care providers. Students recognized the value of each health care professional, and that each had a unique role that helped to facilitate patient care during each care episode. Students recognized the value of being able to obtain hands-on experiences working collaboratively with other health care professionals, and this was often cited as a significant learning point from their service-learning experience. This sentiment was echoed among third-year students, who also valued the opportunity to learn from other health professionals. Additionally, through interprofessional interactions, second- and third-year students were able to observe the role that pharmacists play in a health care team.

The sixth theme identified was that students were left feeling empowered upon completion of the service-learning experience. Second-year student pharmacists most often indicated that they were lacking in confidence in their knowledge and skills prior to the service-learning experience. However, after completing the service-learning experience, they often expressed confidence as well as a feeling of empowerment in their competency and ability to provide patient care. This feeling of confidence was often tied to the level of care entrusted to them by the multidisciplinary health care team. Students also described that the confidence instilled in them through these experiences motivated them to take ownership of their role as a future pharmacist on an interdisciplinary team.
Many third-year student pharmacists commented on their clinical growth as they had progressed through the pharmacy curriculum. Third-year students compared and contrasted their impressions during their second free clinic experience with their initial impressions as secondyear students. Additionally, third-year student pharmacists described being able to put therapeutic concepts and knowledge gained from didactic coursework into practice. With this increased confidence and familiarity with care provision at the free clinics, third-year students felt comfortable mentoring and guiding underclassmen who were new to the experience.

\section{DISCUSSION}

Despite the increasing incorporation of servicelearning experiences in pharmacy curricula and a growing interest in developing socially responsible pharmacists, knowledge of student perceptions upon completion of service-learning experiences is limited. ${ }^{17-18,24}$ The present study is, to our knowledge, the largest study of its kind to assess student perceptions after completion of pharmacyfocused service-learning experiences in free clinics. Our results show that many student pharmacists indicate that providing care to underserved or vulnerable populations is a professional obligation, and this was especially true for patients who had language or cultural barriers. Additionally, experiences working with underserved populations increased empathy for these populations, with some students reporting an overwhelming emotional reaction. Students also indicated that the service-learning experience gave them a greater appreciation for the inequities of our health system. Furthermore, an overwhelming number of students indicated that they found this experience to be valuable, with many students expressing a desire to pursue a career path that focused on underserved populations, volunteer in a similar capacity in the future, or apply the lessons learned to care provision in other settings.

As the profession of pharmacy maintains that health professionals have a moral responsibility to meaningfully engage communities, it is essential to incorporate learning activities in which student pharmacists gain an appreciation for and accept their professional obligation to provide care to those who are vulnerable and disenfranchised early on in their training. ${ }^{14}$ In Schlesselman and colleagues' study on the incorporation of service-learning into US pharmacy curricula, $75.7 \%$ of schools reported providing servicelearning opportunities either as voluntary or required experiences. ${ }^{3}$ However, when Blazejewski and colleagues' assessed pharmacists' perceived barriers to providing nondispensing services to underserved populations, they found a lack of interest in providing this care and that uncertainty regarding where to volunteer significantly predicted 


\section{American Journal of Pharmaceutical Education 2019; 83 (9) Article 7379.}

pharmacists non-involvement with underserved populations. ${ }^{15}$ This reveals a great need to implement servicelearning curricula in pharmacy schools to specifically address pharmacists' professional obligation to provide care to underserved populations. Given that pharmacists are in a unique position to accommodate the many barriers to health care that underserved populations face, it is necessary to instill in student pharmacists not only an awareness of disparities but also a professional obligation to use their skills to minimize health disparities, as addressed in AACP's Center for the Advancement of Pharmaceutical Education (CAPE) Educational Outcomes. ${ }^{16}$ Coffey and colleagues' study assessing the implementation and evaluation of a structured service-learning program in a pharmacy curriculum with the goal to personally involve students in care provision corroborate the importance of professionals to use their time and expertise to benefit those in need of help. ${ }^{17}$

Although students did not explicitly state that the service-learning experience served as a self-transformative experience, many students expressed increased empathy for underserved and vulnerable populations following their experience and expressed interest in pursuing work with underserved populations in the future. This theme was echoed in Chen and colleagues' study in which students who completed service-learning experiences developed a genuine concern for the patients encountered. ${ }^{18}$ Additionally, service-learning experiences that expose students to patients who are dissimilar from themselves enable students to anticipate challenges in terms of communication and interaction with underserved patient populations. ${ }^{19,20}$ The empathy expressed by the second- and third-year student pharmacists in this study underscores the value of student pharmacists having "real life" interaction with patients, and that classroom discussions on the impact of social determinants of health cannot supplant face-to-face experiences with patients. Moreover, a study by Sick and colleagues indicated that exposure to underserved populations through student-run free clinics can improve health professions students' attitudes towards underserved populations over time. ${ }^{21}$

In this study, discussion of equitable health resource distribution led to both positive and negative valuations of the service-learning experience. While most students identified that the distribution of health resources in the US health care system is inequitable, student responses to this injustice varied greatly. Most students expressed empathy for uninsured or underinsured patients who face added barriers to health care that made receiving adequate care challenging. This greater awareness of social determinants of health is similarly reflected in student perceptions regarding caring for patients at a Federally Qualified Health Center (FQHC). ${ }^{18}$ However, some students indicated that free clinics did not address the larger, underlying issue regarding health care in the United States. More commonly, students identified the need for free clinics as part of the safety net system. Stimulating opinions in student pharmacists and discussion of health resource distribution and the health care system as a whole is an important first step to action. A higher awareness and acknowledgment of health disparities can increase initiatives that address disparities and improve access to care. ${ }^{22,23}$ However, it is important to engage students in a dialogue to stimulate deeper discussion of equitable health resource distribution so that they are motivated to bring about change and have the skills to do so.

Students reported that the service-learning experience was valuable and expressed appreciation for the experience. Second-year students expressed a desire to be further engaged in the counseling process and contribute to clinical decisionmaking. This reveals ownership of the student role and a proactive stance towards learning. This sense of value in providing care to underserved populations was also found among students in Coffey and colleagues' study that assessed service-learning in pharmacy curriculum. ${ }^{17}$ Many of the students expressed a desire to pursue additional experiences working with underserved populations, a theme that is reflected in the literature. ${ }^{17,24}$ Additionally, the ability to apply the lessons learned from service-learning experiences to future practice is reiterated in Weiss and colleagues' study assessing student perceptions during introductory servicelearning experiences. ${ }^{25}$ In a study conducted by VanderWielen and colleagues, exposure to underserved patient populations increased the likelihood of medical students pursuing practice in primary care fields and practicing in underserved areas. ${ }^{26}$ Just as more physicians entering primary care fields would have beneficial impacts on health care infrastructure, evidence of exposure to underserved populations having a similar impact on student pharmacists would support the implementation of service-learning experiences in all pharmacy curricula and should be an area for future research.

There were some limitations to this study. This was a retrospective assessment of self-reported perceptions of second- and third-year student pharmacists upon completion of a service-learning experience. Students were required to complete the reflective essays as part of the service-learning curriculum, which may have predisposed the students to providing positive statements regarding their experience. Students were required to submit only one reflection essay each academic year, which hindered the ability to assess changes in students' perceptions pre- and post-experience. Another limitation was the length of the experience. Students were expected to participate in one 3hour clinic session during each academic year. However, even though this experience was shorter than other examples of service learning, students still described important 


\section{American Journal of Pharmaceutical Education 2019; 83 (9) Article 7379.}

learning outcomes. Further study should investigate the impact of students participating in longer service-learning experiences. One final limitation was that students from the class of 2019 submitted two essays, one as second-year students and one as third-year students. However, students had completed this activity in both the second and third year of the curriculum for approximately 10 years, writing reflections after each clinic visit. Therefore, including the same class in both years may have been a helpful addition to highlight some of the changes that take place as students progress through the curriculum. Further study could elucidate the impact of participating in such an activity more than once.

\section{CONCLUSION}

The outcomes revealed in this analysis of reflective essays demonstrates that service-learning experiences create an awareness of civic responsibility and volunteerism among student pharmacists. Students learned that pharmacists can play a key role in caring for underserved populations. Some were inspired to think about the larger role of advocacy and systems change in the elimination of health disparities. These experiences may fuel deeper discussion of health resource distribution and the necessity of providing care for underserved populations.

\section{ACKNOWLEDGMENTS}

The authors appreciate the contributions to data analysis made by Laurel P. Mecca, Allison M. de Almeida, and Elizabeth Herrera Lauer. Additionally, the authors would like to acknowledge the assistance of Rachel A. Chamberlin with codebook revision and development.

\section{REFERENCES}

1. National Quality Forum. A Roadmap for Promoting Health Equity and Eliminating Disparities: The Four I's for Health Equity. https://www. qualityforum.org/Publications/2017/09/A_Roadmap_for_Promoting_Health_ Equity_and_Eliminating_Disparities_The_Four_I_s_for_Health_ Equity.aspx. Accessed May 7, 2018.

2. Agency for Healthcare Research and Quality. 2016 National Healthcare Quality and Disparities Report. https://www.ahrq.gov/ research/findings/nhqrdr/nhqdr16/index.html. Accessed May 7, 2018. 3. Schlesselman L, Borrego M, Bloom TJ, Mehta B, Drobitch RK, Smith T. An assessment of service-learning in 34 us schools of pharmacy follow up on the 2001 professional affairs committee report. Am J Pharm Educ. 2015;79(8):Article 116.

4. Peters SJ, MacKinnon GE. Introductory practice and service learning experiences in us pharmacy curricula. Am J Pharm Educ. 2004;68(1):Article.

5. Nichols-English GJ, White CA, Brooks PJ. Bridging community based pharmacy outreach with service-learning principles. Am J Pharm Educ. 2002;66(2):Article 124.

6. American Pharmacists Association. Code of Ethics. http:// www.pharmacist.com/code-ethics. July 31, 2012. Accessed July 3, 2017.
7. Kearney KR. Impact of a service-learning course on first-year pharmacy students' learning outcomes. Am J Pharm Educ. 2013;77(2):Article 14.

8. Brown B, Heaton PC, Wall A. A service-learning elective to promote enhanced understanding of civic, cultural, and social issues and health disparities in pharmacy. Am J Pharm Educ. 2007;71(1):Article 9. 9. Sevin AM, Hale KM, Brown NV, McAuley JW. Assessing interprofessional education collaborative competencies in servicelearning course. Am J Pharm Educ. 2016;80(2):Article 1. 10. Barner JC. Implementing service-learning in the pharmacy curriculum. Am J Pharm Educ. 2000;64(3):Article 260.

11. Barner JC. First-year pharmacy students' perceptions of their service-learning experience. Am J Pharm Educ. 2000;64(3):Article 266. 12. Meierhofer J, Baumgartner L, Howard K, Lounsbery J, Reidt S, Moon J. Facilitating student pharmacist learning through student-led development of a service-learning opportunity. Curr Pharm Teach Learn. 2013;5(6):611-615.

13. Drab S, Lamsam G, Connor S, DeYoung M. Incorporation of service-learning across four years of the pharmd curriculum. Am J Pharm Educ. 2004;68(2):Article 44.

14. Zweber A, Roche VF, Assemi M, et al. Curriculum recommendations of the AACP-PSSC task force on caring for the underserved. Am J Pharm Educ. 2008;72(3):Article 53.

15. Blazejewski L, Vaidya V, Pinto S, Gaither C. Pharmacists' perceived barriers providing non-dispensing services to underserved populations. J Community Health. 2013;38(5):812-822.

16. Medina MS, Plaza CM, Stowe CD, et al. Center for the Advancement of Pharmacy Education 2013 educational outcomes. Am J Pharm Educ. 2013;77(8):Article 162.

17. Coffey CW, Miller SW, Barnett C, Turberville-Vega V. Service learning: implementation and evaluation in a pharmacy curriculum. Acad Exch Q. 2003;7(2):76.

18. Chen JT, Darbishire PL, Plake KS. Assessing student perceptions of the underserved at a federally qualified health center. Curr Pharm Teach Learn. 2010;2(4):248-254.

19. Schumann W, Moxley DP, Vanderwill W. Integrating service and reflection in the professional development of pharmacy students. Am J Pharm Educ. 2004;68(2):Article 45.

20. Begley K, Haddad AR, Christensen C, Lust E. A health education program for underserved community youth led by health professions students. Am J Pharm Educ. 2009;73(6):Article 98. 21. Sick B, Zhang L, Weber-Main AM. Changes in health professional students' attitudes toward the underserved: impact of extended participation in an interprofessional student-run free clinic. $J$ Allied Health. 2017;46(4):213-219.

22. Britton BV, Nagarajan N, Zogg CK, et al. Awareness of racial/ ethnic disparities in surgical outcomes and care: factors affecting acknowledgment and action. Am J Surg. 2016;212(1):102-108.e102. 23. Benz JK, Espinosa O, Welsh V, Fontes A. Awareness of racial and ethnic health disparities has improved only modestly over a decade. Health Aff. 2011;30(10):1860-1867.

24. Kearney KR. Students' self-assessment of learning through service-learning. Am J Pharm Educ. 2004;68(1):Article 29.

25. Weiss D, Hajjar ER, Giordano C, Joseph AS. Student perception of academic and professional development during an introductory servicelearning experience. Curr Pharm Teach Learn. 2016;8(6):833-839.

26. VanderWielen LM, Vanderbilt AA, Crossman SH, et al. Health disparities and underserved populations: a potential solution, medical school partnerships with free clinics to improve curriculum. Med Educ Online. 2015;20(1):27535-27534. 


\section{American Journal of Pharmaceutical Education 2019; 83 (9) Article 7379.}

Appendix 1. Themes and Supporting Quotes

\begin{tabular}{|c|c|}
\hline Theme & Illustrative Quote \\
\hline $\begin{array}{l}\text { Providing care to the underserved } \\
\text { and vulnerable is a professional } \\
\text { obligation }\end{array}$ & $\begin{array}{l}\text { P2 } \\
\text { "My most significant learning point is that all patients, whether homeless or a celebrity, } \\
\text { deserve and want to be treated like humans. Health care professionals have a duty to the } \\
\text { community and mankind to treat their patients with respect and provide the best care } \\
\text { possible." } \\
\text { "The experience I found most interesting was watching the pharmacist counsel a patient that } \\
\text { couldn't speak English. She worked with the interpreter to be able to have a conversation } \\
\text { with the patient about their medications to make sure that both of them were on the same } \\
\text { page about the patient's medications." } \\
\text { "I was really amazed by the doctor's rapport with the patient. He asked the patient about where } \\
\text { he was from, and when the patient said he was from Kenya the doctor began speaking to him } \\
\text { in Swahili. It turns out the resident had spent } 6 \text { months in Kenya and had picked up a few } \\
\text { common phrases in Swahili. The patient immediately lit up and it was so rewarding to see } \\
\text { what a difference taking the time to talk to the patient and make them comfortable can } \\
\text { make." } \\
\text { "This clinic made me feel like I was fulfilling a professional obligation because it was clear that } \\
\text { all of the uninsured patients needed help and would not have regularly been able to receive } \\
\text { care and medications." } \\
\text { P3 } \\
\text { "It [is] our responsibility as health care professionals to exceed expectations and really do our } \\
\text { best to make the experience less cumbersome and as helpful as possible for the patients } \\
\text { regardless of their past or current circumstances." } \\
\text { "This may not mean taking time to visit a clinic every week, but it may be something as little as } \\
\text { helping patients learn about medication assistance programs or helping patients find } \\
\text { accessible medical care without [judgment]. Pharmacists currently are fighting to be } \\
\text { recognized as providers of patient care, and I believe the underserved population is one of } \\
\text { the biggest arenas in which we can have a positive impact." } \\
\text { tI also had to adjust my communication technique so that I used short sentences to facilitate } \\
\text { translation. These skills are very important to have because underserved populations can } \\
\text { to int at almost any site where I would work as a pharmacist, and I will most definitely have } \\
\text { to with non-English speaking patients in my career." }\end{array}$ \\
\hline
\end{tabular}

(Continued) 
American Journal of Pharmaceutical Education 2019; 83 (9) Article 7379.

(Continued)

\begin{tabular}{|c|c|}
\hline Theme & Illustrative Quote \\
\hline $\begin{array}{l}\text { Working with the underserved } \\
\text { increases empathy for these } \\
\text { populations }\end{array}$ & 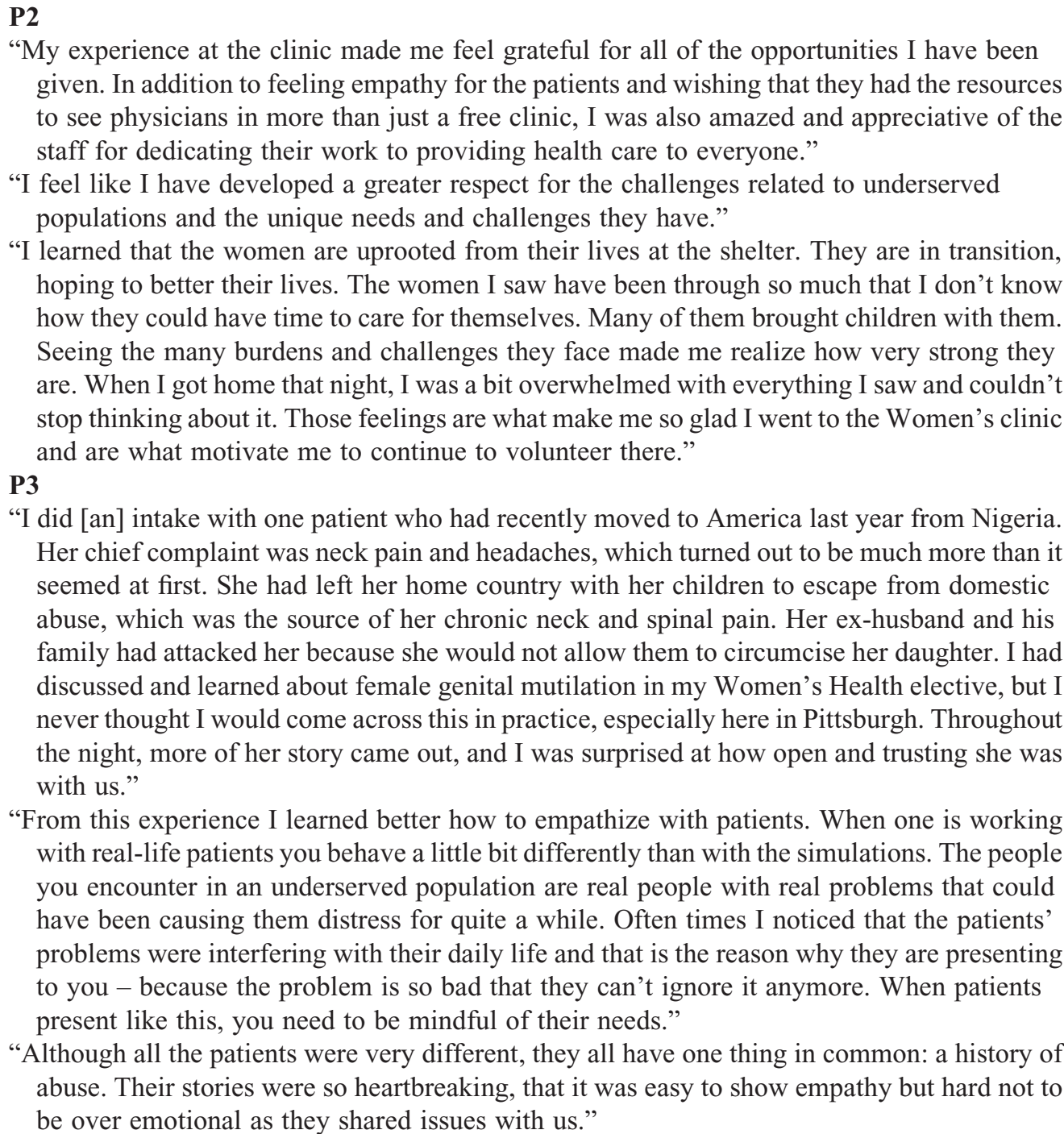 \\
\hline
\end{tabular}

(Continued) 
American Journal of Pharmaceutical Education 2019; 83 (9) Article 7379.

(Continued)

\begin{tabular}{ll}
\hline Theme & Illustrative Quote \\
\hline $\begin{array}{c}\text { Students developed a greater } \\
\text { awareness of the inequities of }\end{array}$ & $\begin{array}{l}\text { P2 } \\
\text { "In that regard, it felt like I made an immediate impact to public health by dispensing to and }\end{array}$
\end{tabular}

the health system

counseling underserved patients. At the same time, however, it felt that there was a much larger underlying issue."

"It is heartbreaking to know that these patients are just given a medication and sent off to deal with the problem. These patients won't have their medical problems resolved because of money. It actually makes me very angry that so much of health care depends on money. I was very upset over this situation and felt frustrated that there was nothing I could do. This setting makes me uncomfortable because I feel there is nothing I can do, but I also feel guilty avoiding these environments because pretending these situations don't exist is much easier. It was a horrible experience."

"I tried to think about how this clinic was making a difference and in the grand scheme of things improving our nation's health care. During this deep thought on my walk home I came to a possibly not so popular conclusion. This underserved clinic was not making a difference in my opinion. You can't seal a hole in a ship with a Band-Aid and expect that to be a solution. Now I am not saying these clinics don't help people, because they do, but they are more of an instant gratification that you helped one person's life [than] really solving a problem."

P3

"Hopefully the number of patients without insurance will start to dwindle when the Affordable Care Act becomes better established. But for now places like the Birmingham Clinic are making basic health care possible for those who do not have the resources for health insurance."

"And given that the clinics are becoming much more prevalent with many sliding-scale and free options, we as a profession and medical providers as a whole need to do a better job of "advertising" them to our safety net patients."

"This [patient's] situation is one that I have seen over and over again throughout my underserved clinic experience. The sad truth is that there are only so many resources and help that we can provide to someone who is unable to afford health insurance."

Providing care to underserved P2

populations in free clinics is a valuable experience

"Now I am very interested in continuing to volunteer my time in underserved clinics in my future as a pharmacy student and also as a pharmacist."

"This experience has led me to consider how I can serve underserved populations in addition to and through the career I wish to pursue in a hospital setting"

"If I were to go again, I would ask to be involved with the development of a discharge plan for patients such that I could contribute my expertise in drug knowledge and as a member of an inter-professional team."

P3

"My most significant learning point from this experience was that no matter what area of pharmacy I found myself in, I will always make time to volunteer my time and skills to either this clinic or one like it. I want to make sure that something like this is present in my future career as a pharmacist."

"I don't plan on working in an underserved [setting] after graduation, but these events have helped me gain a better idea of people/patients in general that could be extrapolated into my future practice."

"In general, it was a rewarding experience to be able to help these women off their feet so that they can face their real troubles with less bothersome ones. It was also rewarding when they thanked us for our help and expressing gratitude for our willingness to give up our free time to help them. And most importantly, this time around I saw, yet again, just how much demand there is for helping the underserved community and just how much more we pharmacy students and pharmacists can contribute." 
American Journal of Pharmaceutical Education 2019; 83 (9) Article 7379.

(Continued)

\begin{tabular}{ll} 
Theme & Illustrative Quote \\
\hline
\end{tabular}

Students experienced a growth in $\mathbf{P 2}$

interprofessional awareness "Most significantly from my experience at the Birmingham Free Clinic, I learned about the value of treating patients as a health care team. No provider can be responsible for knowing everything about everything; by combining a team of field experts, you can provide a patient with overall expert medical care that appropriately and effectively addresses all of his or her needs."

"My most significant learning point from my experience is that you can accomplish a much greater amount as well as a more optimum patient-centered treatment plan when you work efficiently as a team than when you do individually."

"I think that this collaboration between the pharmacists and physicians was the most significant learning point of the whole experience due to application of this collaboration in my future" P3

"I think this experience is important to not only recognize the amount of patients that are underserved and how we can help, but also to understand that in these patients, and with every patient, there is no one health care member that can change the patient. Health care is a collaborative effort."

"One of the great aspects of the Birmingham Clinic is the ability to work on interprofessional teams. It was also helpful to begin practicing patient friendly language, and being able to see how other health care providers and students may approach a patient interaction differently than me."

"The primary care physician respected my understanding in regards to dosing, therapy recommendations, and pregnancy medication safety. I truly felt that she valued my knowledge and that my unique skill set was appreciated"

Students left feeling empowered

P2

upon completion of service-learning experience

"While it was initially intimidating, I felt empowered after offering guidance on medication dosing to the physician."

"I was familiar with almost all of the medications in the cabinet, which made me feel proud of my education and knowledge. This also really reinforced that we are the medication experts."

P3

"Through this experience, I really noticed how much I have learned over the past two years. I have really developed my communication skills. I was able to communicate the information to the patient efficiently and in a way that the patient understood. Additionally, I found it easy to talk to the physician about the medications and the cases. I have gained a lot of drug knowledge. I was able to recall information about the medications and counsel the patient on them."

"However, today's experience taught me that I could do much more than collecting basic information. I utilized clinical knowledge I learned in cardiology, infectious disease, as well as endocrinology to help me dig deeper and collect comprehensive information. My capability to provide care to patients has enhanced as my knowledge base increases."

"Since I was now the returning P3 at Birmingham, I understood the slight level of anxiety my classmate had since this was a new process for her so I took a more active role in counseling the patients and let her observe me and chime in when she felt comfortable. I really enjoyed getting to know the patients and assessing their needs while being a "mentor" for the P2 at this visit to Birmingham Free Clinic."

$\mathrm{P} 2=$ second professional year; $\mathrm{P} 3=$ third professional year 